Supporting information

\title{
Power management and reaction optimization for self-powered electrochemical system driven by triboelectric nanogenerator
}

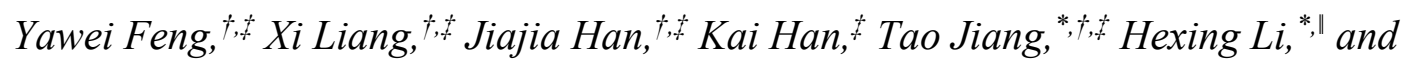
Zhong Lin Wang ${ }^{*}, \dot{t}, \xi$

+ CAS Center for Excellence in Nanoscience, Beijing Key Laboratory of Micro-Nano Energy and Sensor, Beijing Institute of Nanoenergy and Nanosystems, Chinese Academy of Sciences, Beijing 101400, China

* School of Nanoscience and Technology, University of Chinese Academy of Sciences, Beijing 100049, China

" School of Environmental and Chemical Engineering, Shanghai University of Electric Power, Shanghai 200090, China

$\S$ School of Materials Science and Engineering, Georgia Institute of Technology, Atlanta, Georgia 30332-0245, USA

Corresponding authors: zlwang@gatech.edu (Z. L. Wang), jiangtao@binn.cas.cn (T. Jiang), hexing-li@shnu.edu.cn (H. Li) 


\section{METHODS}

Fabrication and Measurement of the CS-TENG. The CS-TENG was fabricated as the following procedure. Two pieces of thin $\mathrm{Cu}$ foils $(10 \mathrm{~cm} \times 10 \mathrm{~cm} \times 30 \mu \mathrm{m})$ were adhered onto two acrylic boards, respectively. A thin FEP film $(10 \mathrm{~cm} \times 10 \mathrm{~cm} \times 30$ $\mu \mathrm{m})$ was adhered to one of the $\mathrm{Cu}$ foils, which was used as the triboelectric layer. Two conductive wires were embedded under the copper foils as the output channels. For better contact condition of the tribo-pair, sponge tapes were used as buffer layers on both acrylic boards. The CS-TENG array was fabricated by the similar method, except for the different areas of copper and FEP films $(3 \mathrm{~cm} \times 3 \mathrm{~cm})$. The CS-TENG device or array was operated at the frequency of $1 \mathrm{~Hz}$ by a linear motor at the separation distance of $7 \mathrm{~mm}$, maximum speed of $0.2 \mathrm{~m} \mathrm{~s}^{-1}$, acceleration of $0.15 \mathrm{~m} \mathrm{~s}^{-2}$, deceleration of $0.125 \mathrm{~m} \mathrm{~s}^{-2}$, and waiting time of 47.5 and $45 \mathrm{~ms}$ in the falling and raising processes. The Keithley 6514 system electrometer was employed to record the output characteristics, including voltage, current and transferred charges.

Preparation and Electrochemical Characterization of Cathode Electrode: Modified graphite felt was prepared according to the previous reports. ${ }^{[1,2]}$ Before modification, the graphite felt ( $3 \mathrm{~mm}$ in thickness) was cut into the size of $1 \mathrm{~cm} \times 2.5$ $\mathrm{cm}$, washed with the mixture of acetone, alcohol and deionized water in ultrasonic bath, and then dried at $80{ }^{\circ} \mathrm{C} .0 .3 \mathrm{~g}$ mesoporous carbon black, $0.9 \mathrm{~g}$ nano-sized polytetrafluoroethylene (PTFE) powder, $30 \mathrm{~mL}$ deionized water and $2 \mathrm{~mL} \mathrm{n}$-butanol were mixed under stirring for $40 \mathrm{~min}$ to form a dispersed suspension. The cleaned graphite felts were immersed into the above suspension under magnetic stirring for 30 min for the loading of carbon black and PTFE. After being dried and annealed at $360{ }^{\circ} \mathrm{C}$ for $1 \mathrm{~h}$ at a heating rate of $6{ }^{\circ} \mathrm{C} \min ^{-1}$, modified cathode was obtained.

An electrochemical workstation (CHI660E) was used to record the linear sweep voltammetry (LSV) of the modified felt in the three-electrode system at a scanning rate of $10 \mathrm{mV} \mathrm{s}^{-1} . \mathrm{Na}_{2} \mathrm{SO}_{4}$ aqueous solution $(0.5 \mathrm{M})$ was used as the supporting electrolyte solution, and the modified graphite felt was used as the working electrode. A platinum 
sheet $(10 \mathrm{~mm} \times 20 \mathrm{~mm} \times 0.1 \mathrm{~mm})$ acted as the counter electrode and an $\mathrm{Ag} / \mathrm{AgCl}$ electrode acted as the reference electrode.

Construction and Electrochemical Characterization of SPECS. A polylactic acid (PLA) vessel with a volume of $2 \mathrm{~mL}$ and a cover was prepared by three-dimensional printing technology, and was used as the electrolyser device. In order to restrain the hydrophilicity of PLA and maintain the electrolyte solution, the printed vessel was treated with hydrophobic coating. The SPECS includes the CS-TENG or CS-TENG array, the power management module, the energy storage module and the electrolyser. The CS-TENG array was operated at the frequency of $1 \mathrm{~Hz}$ by a linear motor at the same parameters as those in performance measurements. The supplied voltage or current to the electrolyser in SPECS was measured by the Keithley 6514 system electrometer.

Generation and Measurement of $\mathrm{H}_{2} \mathrm{O}_{2}$ : The electro-generation of $\mathrm{H}_{2} \mathrm{O}_{2}$ was carried out in the PLA-printed vessel. A modified graphite felt was used as the cathode electrode, a Pt sheet $(10 \mathrm{~mm} \times 20 \mathrm{~mm} \times 0.1 \mathrm{~mm})$ was used as the anode, and $1.5 \mathrm{~mL}$ $\mathrm{Na}_{2} \mathrm{SO}_{4}$ aqueous solution $(0.5 \mathrm{M})$ was used as the electrolyte solution. No additional acid or alkali was dropped to adjust the $\mathrm{pH}$ value of the $\mathrm{Na}_{2} \mathrm{SO}_{4}$ solution. Besides, no $\mathrm{O}_{2}$ or airflow was injected into the solution in the whole process. For the electrocatalytic simulation of $\mathrm{H}_{2} \mathrm{O}_{2}$ generation, a DC-power-charged supercapacitor was used as the power source, and a mechanical switch was used to release the stored electric energy. The voltage change was measured by the Keithley 6514 system electrometer, while the current change was monitored by the CHI660E electrochemical workstation. For the self-powered $\mathrm{H}_{2} \mathrm{O}_{2}$ generation, the CS-TENG with power management module and energy storge module was used as the power source to supply the electrolyser. After a certain period of time, $0.9 \mathrm{~mL}$ solution was pipette out from the vessel for the quantitative detection of $\mathrm{H}_{2} \mathrm{O}_{2}$ concentration. The analysis method was referenced to the spectrophotometric determination (Shimadzu UV3600) using the titanium reagent (20 mM potassium titanium(IV) oxalate, $1 \mathrm{M}$ sulphuric acid). ${ }^{[3]}$

Fabrication and Characterization of $\mathrm{Cu}-\mathrm{C}_{3} \mathrm{~N}_{4}: \mathrm{Cu}-\mathrm{C}_{3} \mathrm{~N}_{4}$ was synthesized according to a previous report. ${ }^{[4]} 0.287 \mathrm{~g}$ of $\mathrm{Cu}\left(\mathrm{NO}_{3}\right)_{2} \cdot 3 \mathrm{H}_{2} \mathrm{O}$ was dissolved into $2 \mathrm{~g}$ of 
cyanamide (50 wt $\%$ in water) in a $20 \mathrm{~mL}$ of glass vial. After being covered by a piece of aluminum foil with four pierced holes, the vial was placed in a muffle furnace. The precursor was heated to $550{ }^{\circ} \mathrm{C}$ within $40 \mathrm{~min}$, and maintained for $1 \mathrm{~h}$, then $\mathrm{Cu}-\mathrm{C}_{3} \mathrm{~N}_{4}$ product was collected. The aberration-corrected high-angle annular dark-field (HAADF) scanning transmission electron microscopy (STEM) images were taken on a JEM-ARM300F operated at $300 \mathrm{kV}$. The X-ray photoelectron spectroscopy (XPS) spectra were collected using a Thermo Scientific K-Alpha+ with an Al Ka source.

Degradation of Organic Compounds: Organic compound degradation was ex-situ conducted in a vessel. $1 \mathrm{~g} \mathrm{~L}^{-1}$ of $\mathrm{Cu}-\mathrm{C}_{3} \mathrm{~N}_{4}$ was used as the catalyst to form $\cdot \mathrm{OH}$ via $\mathrm{H}_{2} \mathrm{O}_{2}$ decomposition. The $\cdot \mathrm{OH}$ concentration was quantitatively measured by determination of the fluorescence intensity (Edinburgh instruments, FLS980-S2S2-stm) of 2hydroxyterephthalic acid evolved from hydroxylated terephthalic acid. ${ }^{[5]}$ For the pollutant degradation, concentrated Rhodamine $\mathrm{B}(\mathrm{RhB})$ or formaldehyde $\left(\mathrm{CH}_{2} \mathrm{O}\right)$ solution was dropped into the collected $\mathrm{H}_{2} \mathrm{O}_{2}$ aqueous solution. Before the addition of $1 \mathrm{~g} \mathrm{~L}^{-1}$ catalyst, Rhodamine $\mathrm{B}(\mathrm{RhB})$ solution or formaldehyde $\left(\mathrm{CH}_{2} \mathrm{O}\right)$ solution was dropped into the $\mathrm{H}_{2} \mathrm{O}_{2}$ solution to form a hybrid solution. The $\mathrm{H}_{2} \mathrm{O}_{2}$ concentration was maintained to be about $100 \mathrm{mg} \mathrm{L}^{-1}, \mathrm{RhB}$ concentration was $10 \mathrm{mg} \mathrm{L}^{-1}$, and $\mathrm{CH}_{2} \mathrm{O}$ concentration was $2.5 \mathrm{mg} \mathrm{L}^{-1}$. All the experiments were performed in the dark to avoid the photocatalysis effect of $\mathrm{Cu}-\mathrm{C}_{3} \mathrm{~N}_{4}$. The concentration of $\mathrm{RhB}$ dye was directly determined by spectrophotometer (Shimadzu UV 3600) at the characteristic absorption peak. The concentration of $\mathrm{CH}_{2} \mathrm{O}$ was determined by acetylacetone spectrophotometric method. ${ }^{[6]}$

\section{REFERENCES}

(1) Feng, Y.; Han, K.; Jiang, T.; Bian, Z.; Liang, X.; Cao, X.; Li, H.; Wang, Z. L., Self-powered electrochemical system by combining Fenton reaction and active chlorine generation for organic contaminant treatment. Nano Res. 2019, 12, 2729-2735. 
(2) Yu, F.; Zhou, M.; Yu, X., Cost-effective electro-Fenton using modified graphite felt that dramatically enhanced on $\mathrm{H}_{2} \mathrm{O}_{2}$ electro-generation without external aeration. Electrochim. Acta 2015, 163, 182-189.

(3) Sellers, R. M., Spectrophotometric determination of hydrogen peroxide using potassium titanium(IV) oxalate. Analyst 1980, 105, 950-954.

(4) Xu, J. W.; Zheng, X. L.; Feng, Z. P.; Lu, Z. Y.; Zhang, Z. W.; Huang, W.; Li, Y. B.; Vuckovic, D.; Li, Y. Q.; Dai, S.; Chen, G. X.; Wang, K. C.; Wang, H. S.; Chen, J. K.; Mitch, W.; Cui, Y., Organic wastewater treatment by a single-atom catalyst and electrolytically produced $\mathrm{H}_{2} \mathrm{O}_{2}$. Nat. Sustain. 2021, 4, 147-153.

(5) Barreto, J. C.; Smith, G. S.; Strobel, N. H. P.; McQuillin, P. A.; Miller, T. A., Terephthalic acid: A dosimeter for the detection of hydroxyl radicals in vitro. Life Sci. 1994, 56, PL89-PL96.

(6) National environmental protection standards of PRC, HJ 601-2011, Water quality - Determination of formaldehyde - Acetylacetone spectrophotometric method. 
a)
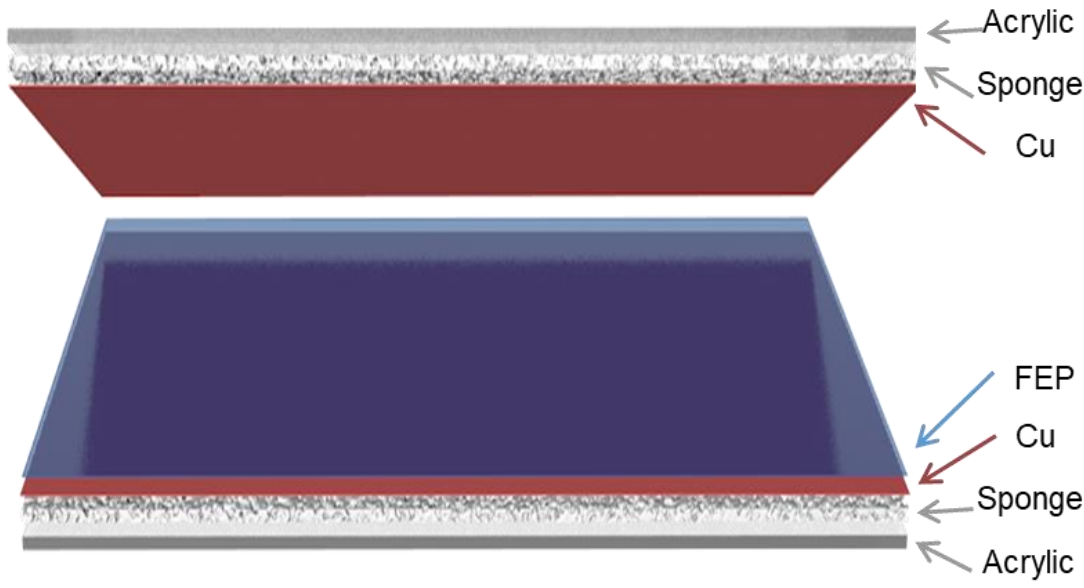

b)

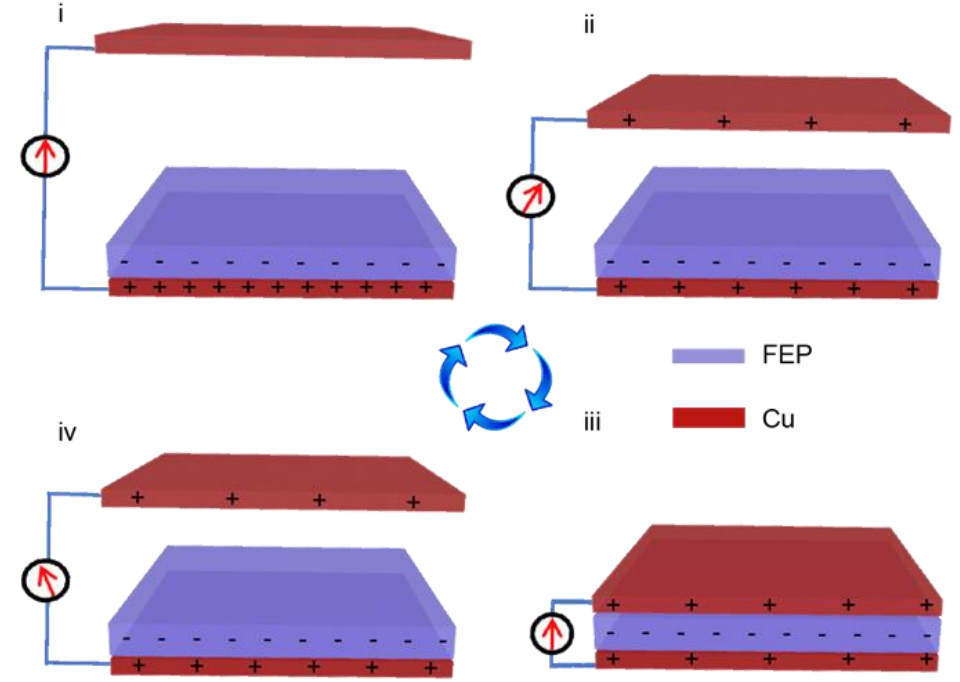

Figure S1. (a) Structural design and (b) schematic diagram showing the energy output mechanism of the CS-TENG. When contacted with $\mathrm{Cu}$ film (upper electrode in Figure $\mathrm{S} 1 \mathrm{~b})$, FEP film is negatively charged according to the triboelectric series. After several cycles of contact-separation operation, the negative charge density upon FEP surface turns to be saturated. Defining the special state (state i) when the top $\mathrm{Cu}$ electrode is far infinitely away from the FEP film as the initial state, the bottom $\mathrm{Cu}$ electrode is positively charged due to the electrostatic induction, while the top electrode is with no charges. When an external force is applied (state i-ii-iii), top $\mathrm{Cu}$ electrode is close to the bottom FEP film (compression state), while positive charges are induced on the top $\mathrm{Cu}$ electrode, and the extra electrons flow to the bottom electrode through the loading circuit, resulting in a unidirectional current pulse. As for the release process (state iiiiv-i), the situation is reversed. The reduced charge density on the top electrode leads to the backward of electrons, and an inversive current pulse signal appears. During the 
periodic press and release of TENG, the electrons flow back and forth through the external circuit, resulting in the alternating current. This is the energy output principle of the CS-TENG. For the designed CS-TENG as shown in Figure S1a, there are sponge layers between acrylic substrates and $\mathrm{Cu}$ electrodes, which play the role of buffer layers. Thus, the falling speed and rising speed of top $\mathrm{Cu}$ electrode in compression and release process are different, contributing to the different magnitudes of positive and negative short-circuit current peaks during the separating-contacting processes.

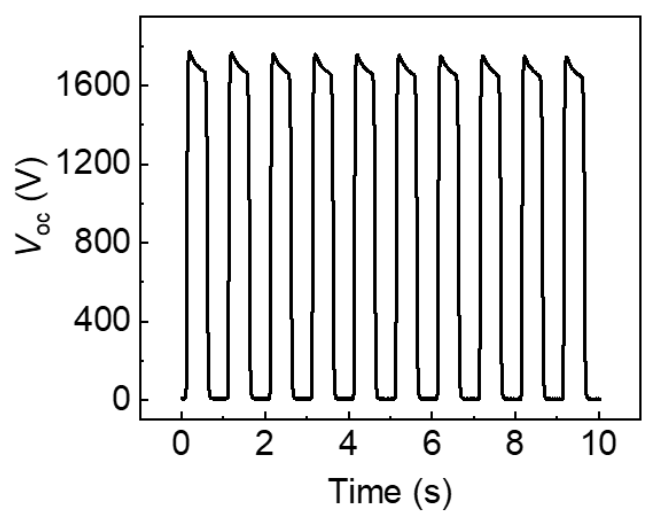

Figure S2. $V_{\mathrm{OC}}$ profile of the CS-TENG. The result was measured by using Trek model 347 electrometer and Keithley 6514 system electrometer. 

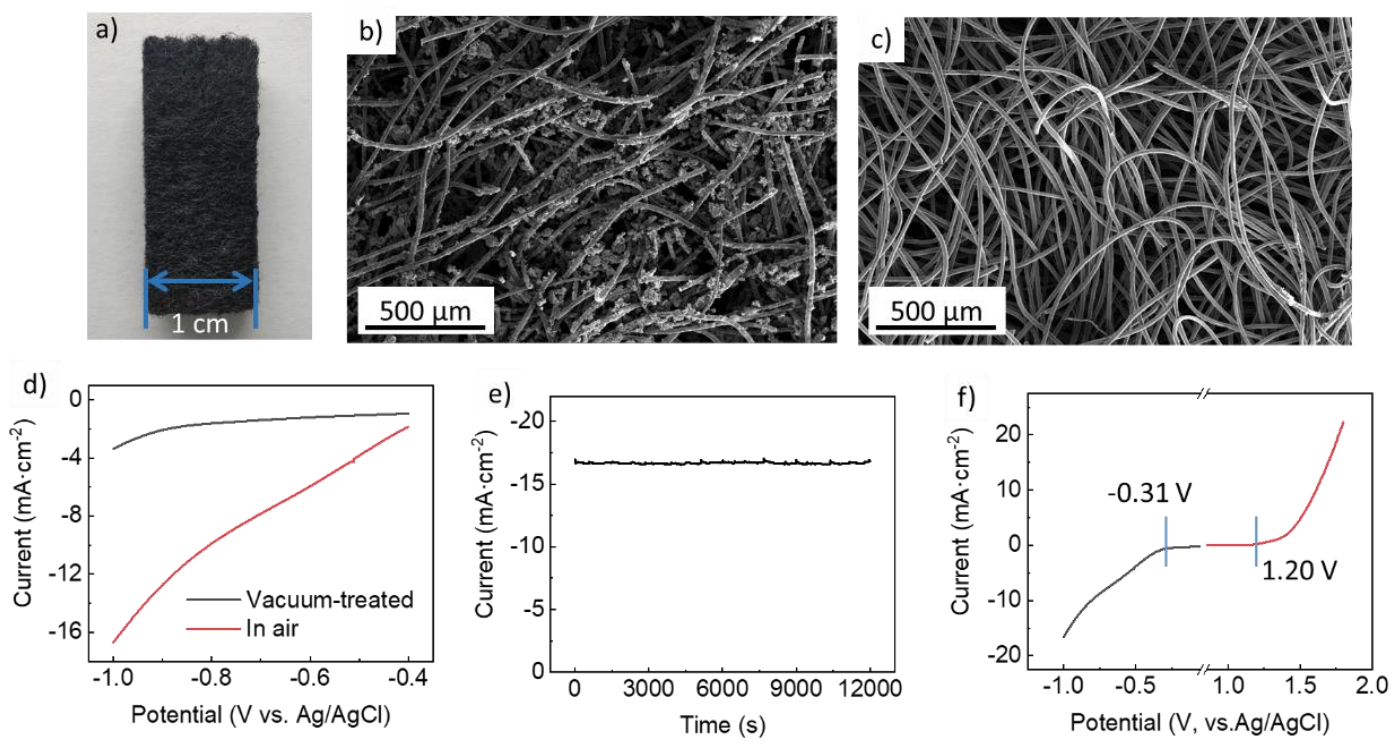

Figure S3. (a) A photograph and (b) scanning electron microscope (SEM) image of the modified graphite felt. (c) The SEM image of the surface of the original graphite felt. (d) Linear sweep voltammetry of the modified graphite felt cathode in air and at the vacuum-treated condition. (e) Long-term current change under the potential of $-1.0 \mathrm{~V}$ vs. $\mathrm{Ag} / \mathrm{AgCl}$. (f) Linear sweep voltammetry of the modified graphite felt cathode and the $\mathrm{Pt}$ sheet in $0.5 \mathrm{M} \mathrm{Na}_{2} \mathrm{SO}_{4}$ solution at the scan rate of $10 \mathrm{mV} / \mathrm{s}$.

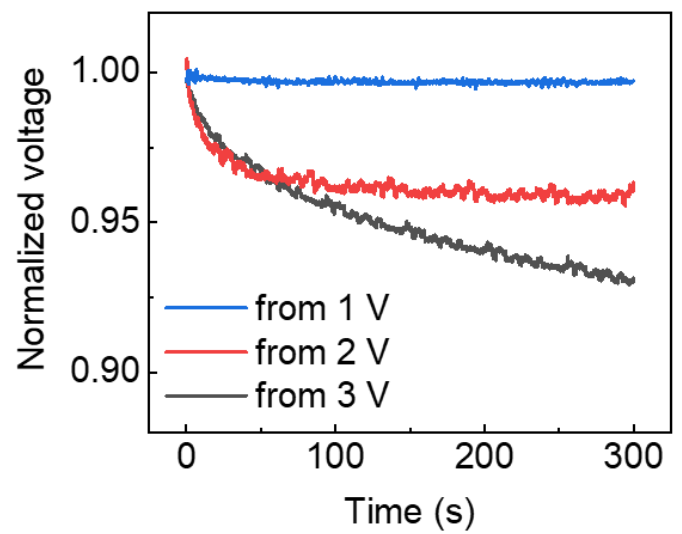

Figure S4. The self-discharging characteristic of a $22 \mathrm{mF}$ supercapacitor at different initial voltages. 

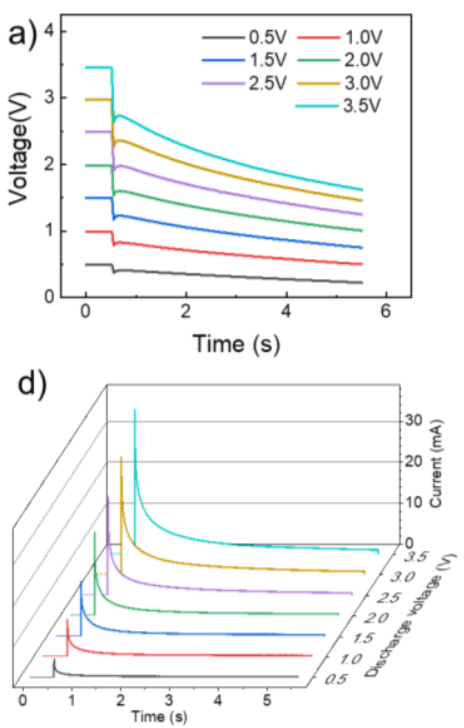
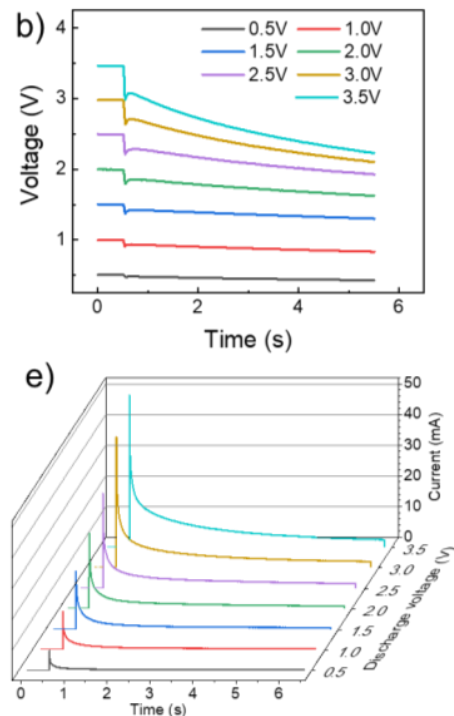
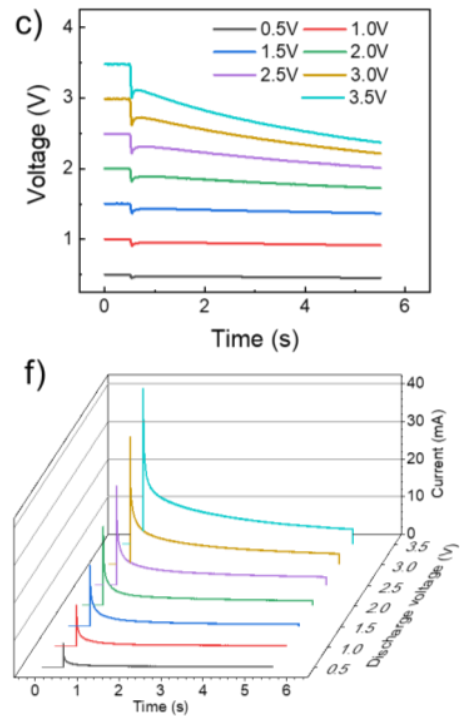

Figure S5. (a-c) Voltage on the electrolyser and (d-f) flowing current through the electrolyser by discharging different supercapacitors from different initial voltages (a and d: $10 \mathrm{mF}$; $b$ and e: $32 \mathrm{mF}$; $c$ and f: $47 \mathrm{mF}$ ). 
Table S1. A summary of the electrochemical simulation results powered by different supercapacitors.

\begin{tabular}{|c|c|c|c|c|c|c|c|c|c|c|c|c|c|c|c|c|}
\hline & \multicolumn{4}{|c|}{$10 \mathrm{mF}$} & \multicolumn{4}{|c|}{$22 \mathrm{mF}$} & \multicolumn{4}{|c|}{$32 \mathrm{mF}$} & \multicolumn{4}{|c|}{$47 \mathrm{mF}$} \\
\hline & $Q_{1}$ & $Q_{\text {tol }}$ & $C_{\mathrm{H}_{2} \mathrm{O}_{2}}$ & $F E$ & $Q_{1}$ & $Q_{\text {tol }}$ & $C_{\mathrm{H}_{2} \mathrm{O}_{2}}$ & $F E$ & $Q_{1}$ & $Q_{\mathrm{tol}}$ & $C_{\mathrm{H}_{2} \mathrm{O}_{2}}$ & $F E$ & $Q_{1}$ & $Q_{\text {tol }}$ & $C_{\mathrm{H}_{2} \mathrm{O}_{2}}$ & $F E$ \\
\hline $0.5 \mathrm{~V}$ & 2.7 & 143.3 & 3.82 & $22.3 \%$ & 3.1 & 187.2 & 8.68 & $38.7 \%$ & 2.5 & 89.8 & 3.65 & $34.0 \%$ & 2.3 & 82.5 & 2.19 & $22.2 \%$ \\
\hline $1.0 \mathrm{~V}$ & 4.9 & 296.4 & 6.94 & $19.6 \%$ & 6.6 & 396.8 & 16.61 & $34.9 \%$ & 5.2 & 187.8 & 6.87 & $30.5 \%$ & 4.1 & 147.4 & 3.89 & $22.0 \%$ \\
\hline $1.5 \mathrm{~V}$ & 7.5 & 448.4 & 6.32 & $11.8 \%$ & 10.2 & 614.4 & 15.52 & $21.5 \%$ & 6.5 & 195.4 & 6.77 & $29.0 \%$ & 6.5 & 195.2 & 5.05 & $21.6 \%$ \\
\hline $2.0 \mathrm{~V}$ & 9.8 & 587.7 & 13.57 & $19.3 \%$ & 13.1 & 784.2 & 18.31 & $19.5 \%$ & 11.9 & 285.5 & 7.14 & $20.9 \%$ & 13.0 & 311.0 & 6.79 & $18.3 \%$ \\
\hline $2.5 \mathrm{~V}$ & 12.4 & 496.7 & 15.50 & $26.1 \%$ & 16.6 & 499.4 & 12.01 & $20.1 \%$ & 18.2 & 328.1 & 7.50 & $19.2 \%$ & 22.6 & 407.6 & 8.77 & $18.0 \%$ \\
\hline $3.0 \mathrm{~V}$ & 15.2 & 454.9 & 13.51 & $24.8 \%$ & 24.4 & 366.6 & 8.86 & $21.2 \%$ & 28.0 & 280.0 & 6.24 & $18.6 \%$ & 36.4 & 363.8 & 7.21 & $16.6 \%$ \\
\hline $3.5 \mathrm{~V}$ & 18.4 & 367.9 & 11.69 & $26.5 \%$ & 30.3 & 363.7 & 8.69 & $20.0 \%$ & 39.6 & 395.6 & 6.69 & $14.1 \%$ & 52.1 & 520.7 & 7.51 & $12.0 \%$ \\
\hline
\end{tabular}

Notes:

1. $Q_{1}$ : transferred charges in one discharge cycle, $\mathrm{mC}$;

2. $Q_{\mathrm{tol}}$ : total transferred charges in the conducted discharge cycles, $\mathrm{mC}$;

3. $C_{\mathrm{H}_{2} \mathrm{O}_{2}}$ : the concentration of generated $\mathrm{H}_{2} \mathrm{O}_{2}, \mathrm{mg} / \mathrm{L}$;

4. FE: Faraday efficiency calculated by Equation 5 . 
a)

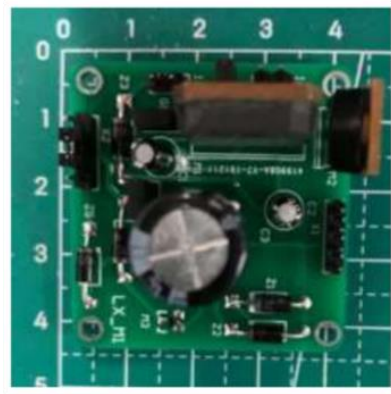

c)

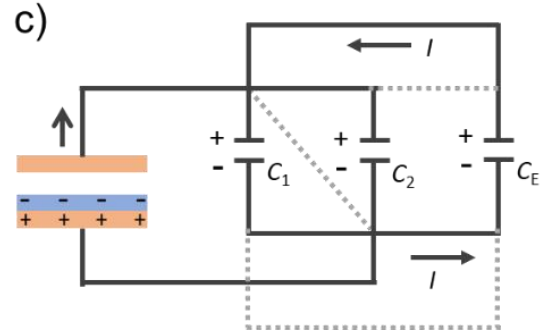

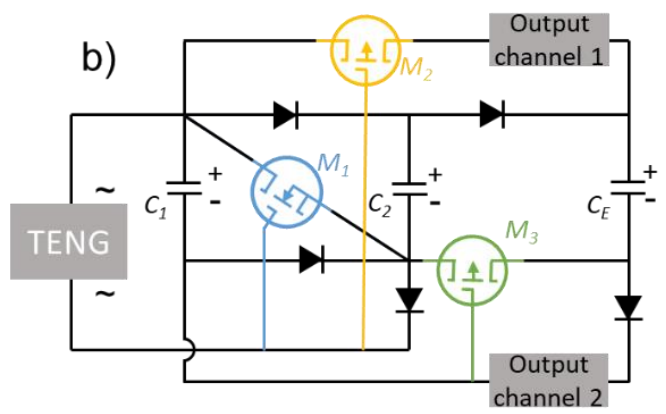

d)

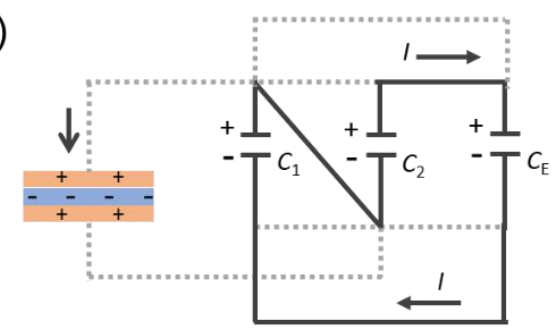

Figure S6. (a) A photo of the printed circuit with the size of $4 \mathrm{~cm} \times 4 \mathrm{~cm}$ and (b) its topological structure circuit diagram. (c-d) Simplified circuit diagrams of the CEC when the CS-TENG inputs (c) positive power and (d) negative power. The dashed lines represent the open-circuit state, while solid lines represent the on state. The normal operation of $\mathrm{CEC}$ requires a certain voltage value on the $C_{\mathrm{E}}$, so the $C_{\mathrm{E}}$ was pre-charged to $6 \mathrm{~V}$ by the CS-TENG array or other methods. During the separation period of the CS-TENG array for positive energy input (Figure S6c), $M_{2}$ and $M_{3}$ are on, while $M_{1}$ is off. Since the voltage on $C_{\mathrm{E}}$ is higher than that on the paralleling capacitor set, the voltage on $C_{\mathrm{E}}$ slightly drops to charge the paralleling $C_{1}$ and $C_{2}$ under the combined action of the CS-TENG array, inducing a transient current $I_{1}$ in this process (Figure $3 \mathrm{a}$ ). Conversely for the negative input at contact period of the array (Figure S6d), $M_{1}$ is switched on, but $M_{2}$ and $M_{3}$ are turned off, and the connection manner of $C_{1}$ and $C_{2}$ becomes in series, leading to almost doubled voltage on them. At this moment, the voltage on the capacitor set of $C_{1}$ and $C_{2}$ is higher than that on $C_{\mathrm{E}}$. Hence, the voltage declines on both capacitors to charge $C_{\mathrm{E}}$, inducing a transient current $I_{2}$ in the period. 
a)

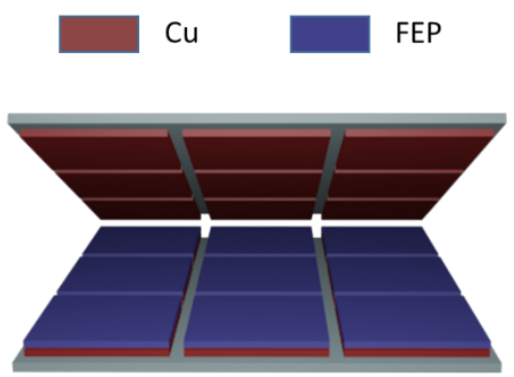

c)

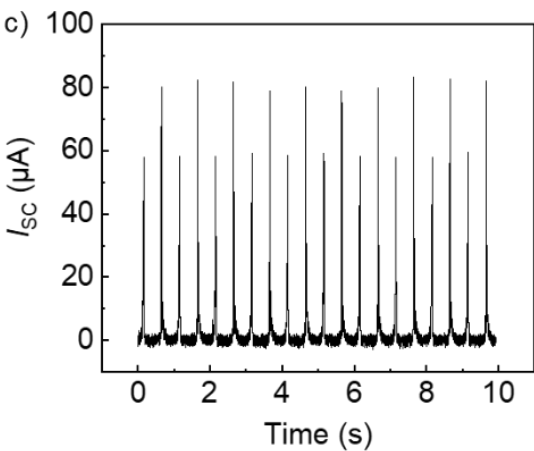

b)

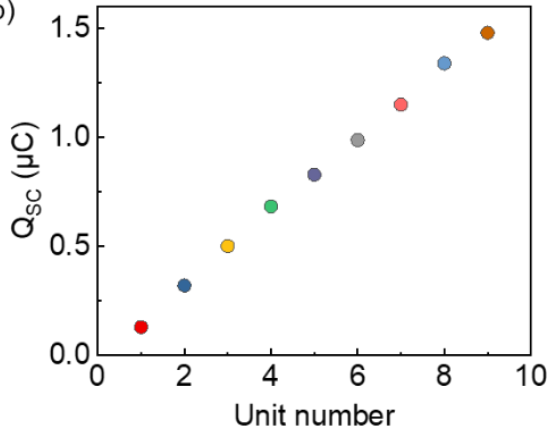

d)

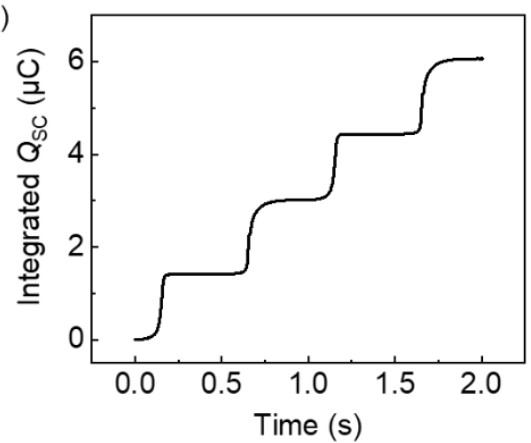

Figure S7. (a) A schematic diagram of the CS-TENG array. (b) The total transferred charges $\left(Q_{\mathrm{SC}}\right)$ when different numbers of CS-TENG units are connected in parallel. (c) The short-circuit current $\left(I_{\mathrm{SC}}\right)$ of the array. (d) The integrated $Q_{\mathrm{SC}}$ from the result of $I_{\mathrm{SC}}$.

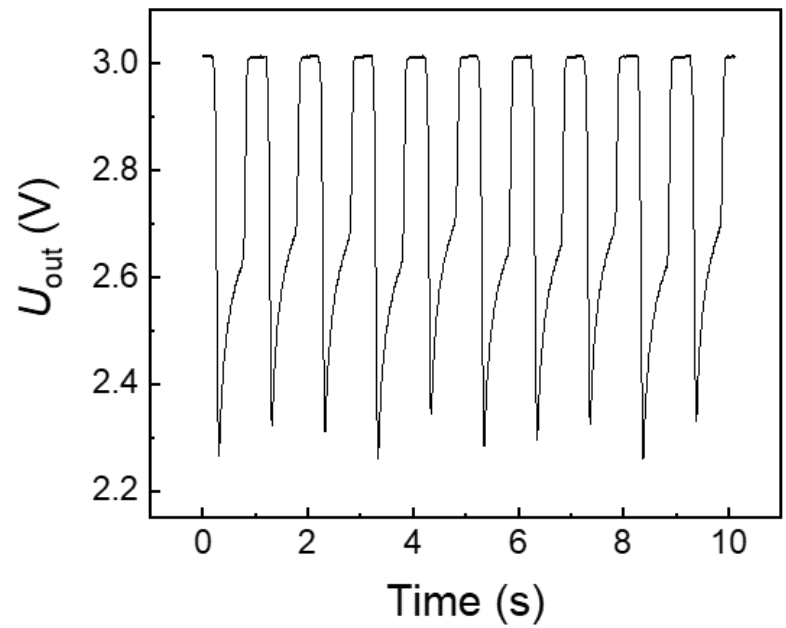

Figure S8. The waveform of voltage on channel 2 without resistance loading measured by the electrometer. 


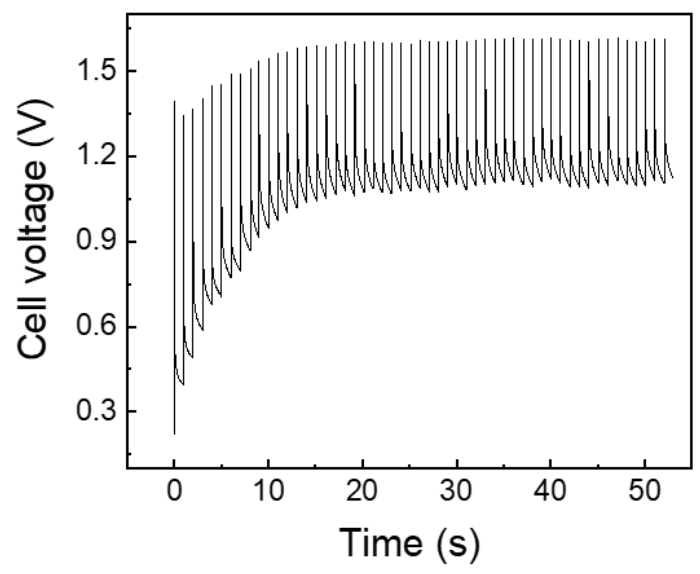

Figure S9. The voltage change on the electrolyser when powered by the CECintegrated CS-TENG array.

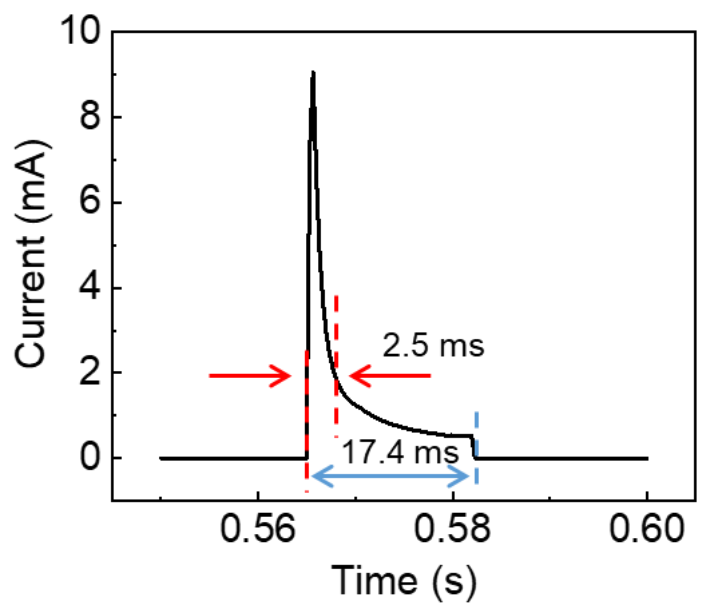

Figure S10. An extracted current peak flowing through the electrolyser in the SPECS. 


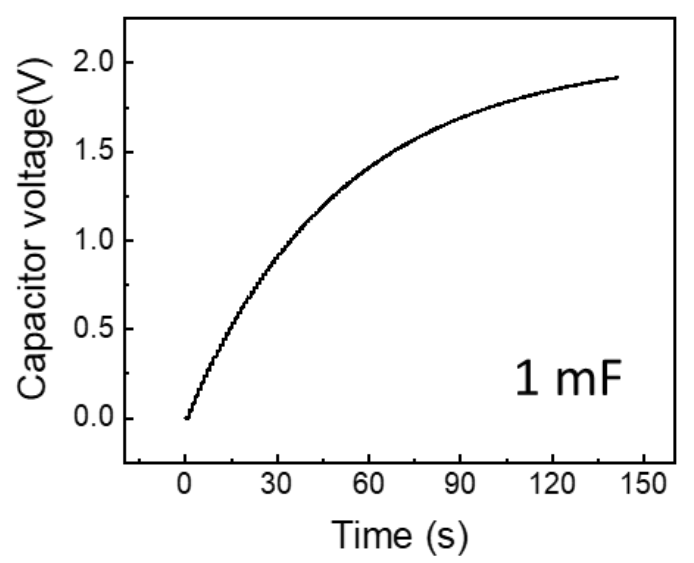

Figure S11. Charging performance for $1 \mathrm{mF}$ capacitor by the CS-TENG array integrated with the CEC.

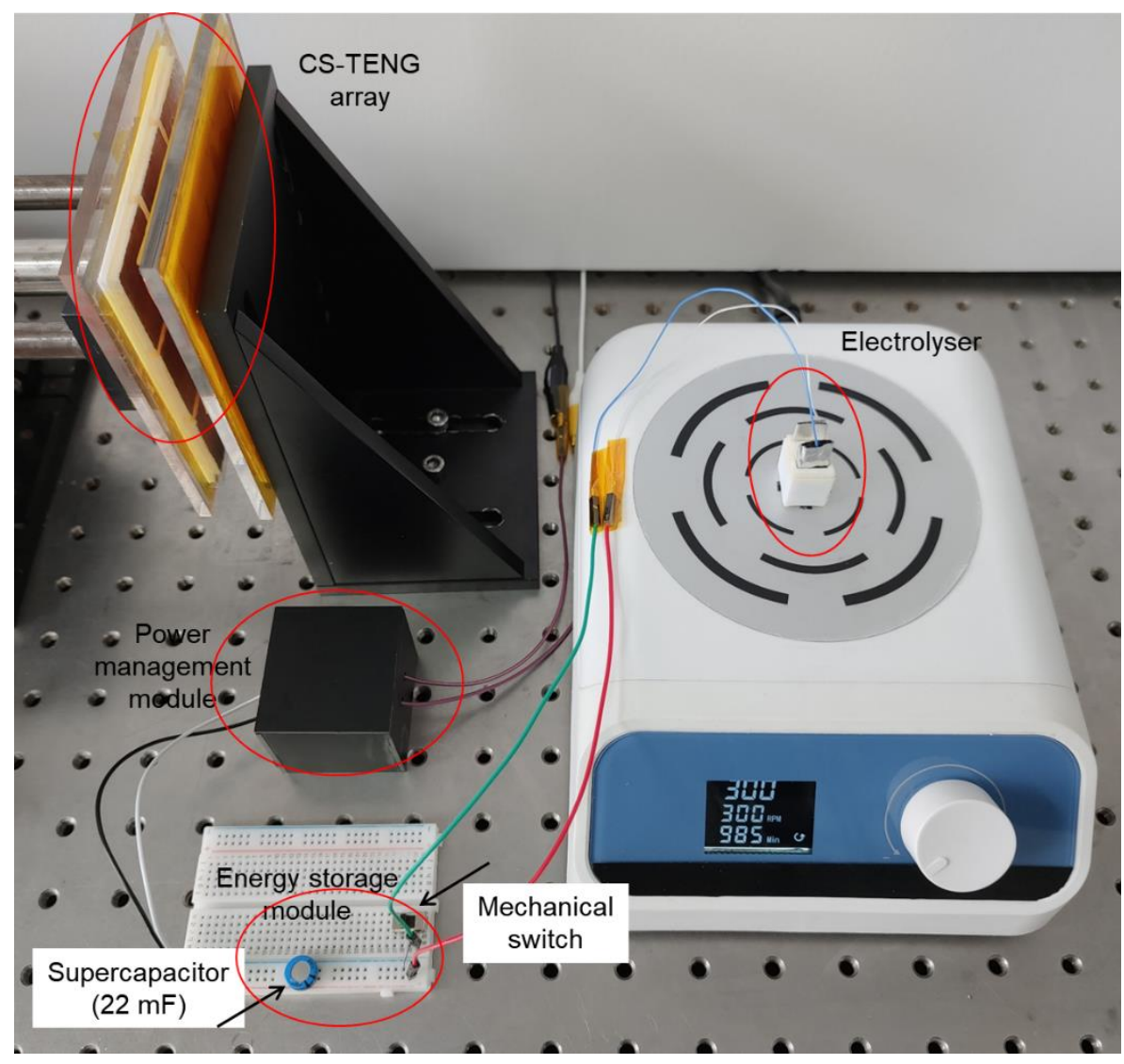

Figure S12. A photograph showing all the parts of SPECS, including the CS-TENG array, the power management module, a $22 \mathrm{mF}$ supercapacitor, a mechanical switch, and an electrolyser. 

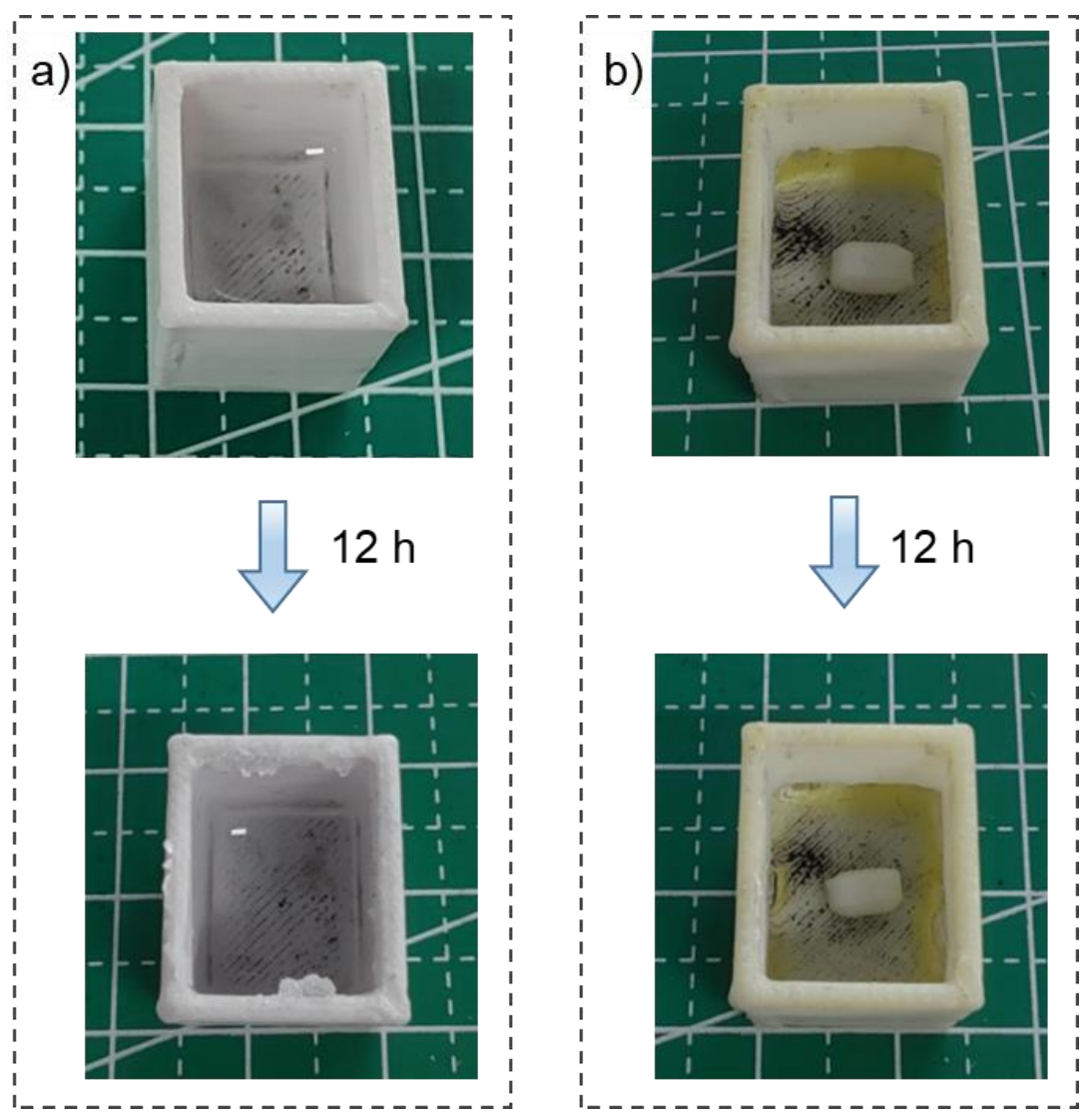

Figure S13. Photographs of the PLA-printed electrolysers (a) before and (b) after hydrophobic treatment. After treatment, less than $0.1 \mathrm{~mL}$ of solution was dissipated after $12 \mathrm{~h}$. As for the untreated electrolyser, only $0.4 \mathrm{~mL}$ of electrolyte solution could be collected. 

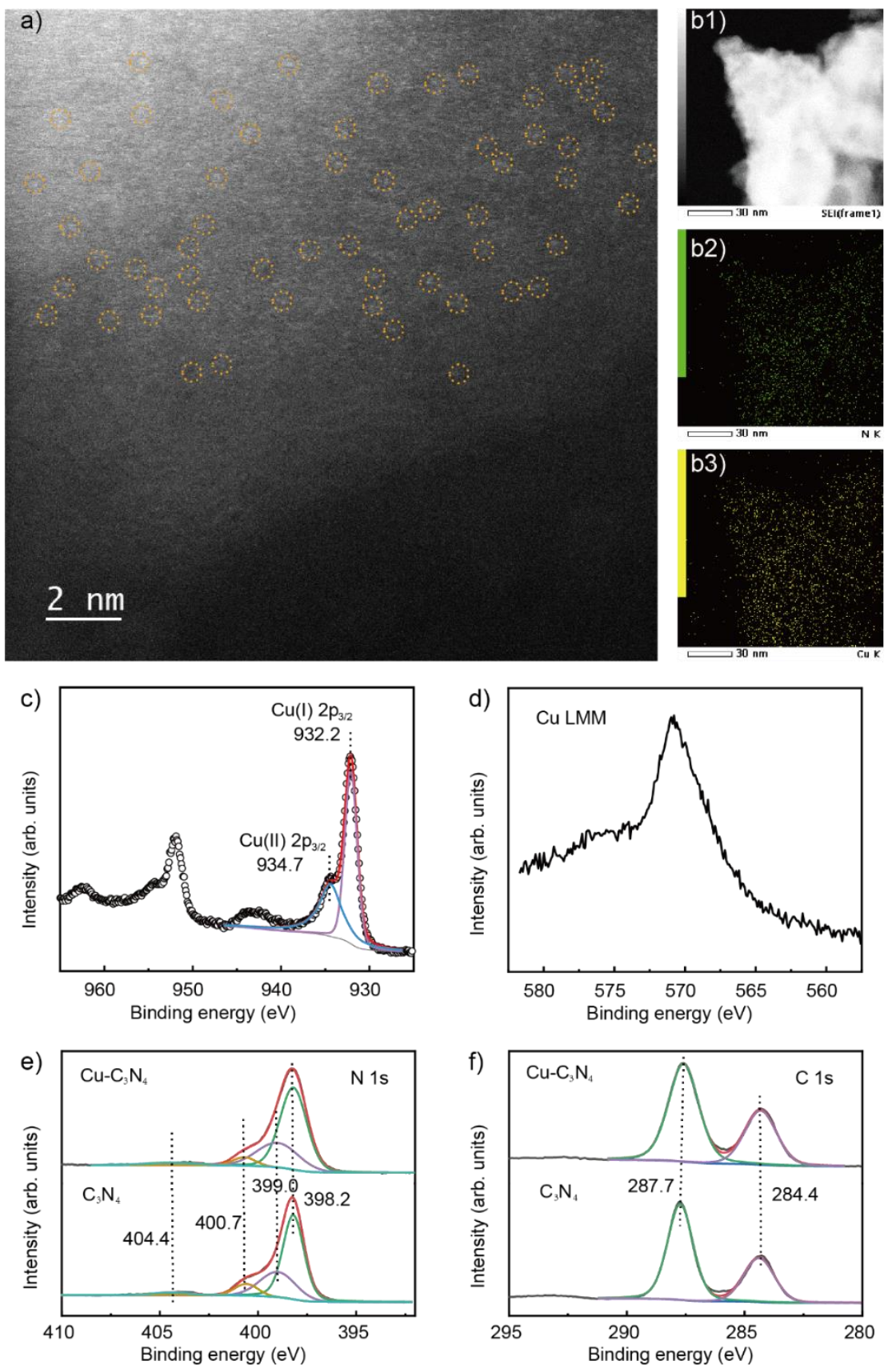

Figure S14. Characterization of $\mathrm{Cu}-\mathrm{C}_{3} \mathrm{~N}_{4}$. (a) Aberration-corrected high-angle annular dark-field (HAADF) scanning transmission electron microscopy (STEM) image of $\mathrm{Cu}$ $\mathrm{C}_{3} \mathrm{~N}_{4}$. Circles indicate single $\mathrm{Cu}$ atoms. (b) Energy dispersive $\mathrm{X}$-ray spectroscopy for elemental mapping of $\mathrm{N}$ and $\mathrm{Cu}$ in the sample. (c) $\mathrm{Cu} 2 \mathrm{p}$ X-ray photoelectron spectroscopy (XPS) spectrum and (d) $\mathrm{Cu}$ LMM Auger spectrum for $\mathrm{Cu}-\mathrm{C}_{3} \mathrm{~N}_{4}$. (e) $\mathrm{N} 1 \mathrm{~s}$ and (f) $\mathrm{C} 1 \mathrm{~s}$ XPS spectra of $\mathrm{Cu}-\mathrm{C}_{3} \mathrm{~N}_{4}$ and $\mathrm{C}_{3} \mathrm{~N}_{4}$. 


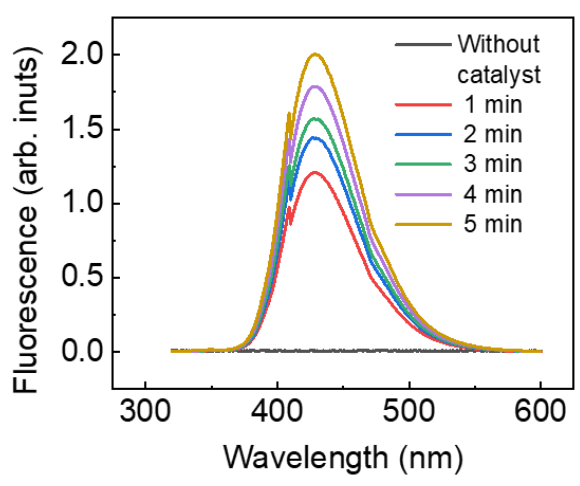

Figure S15. Photoluminescence intensity of 2-hydroxyterephthalic acid evolved from hydroxylated terephthalic acid for the quantitative measurement of $\bullet \mathrm{OH}$ generated from $\mathrm{H}_{2} \mathrm{O}_{2}$ via Fenton process.

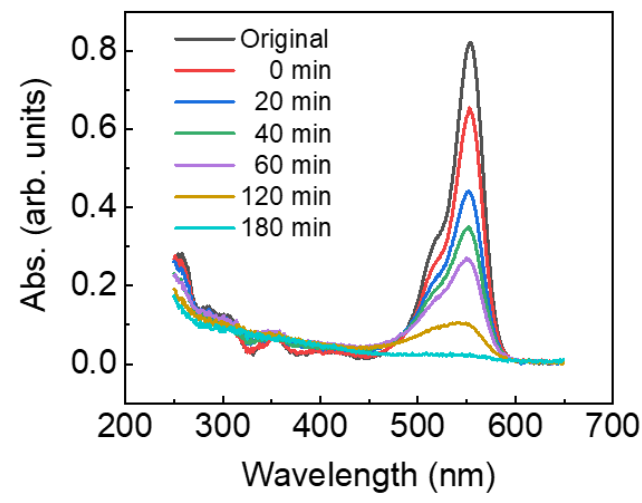

Figure S16. Absorption spectrum of $\mathrm{RhB}$ dye solution as a function of time.

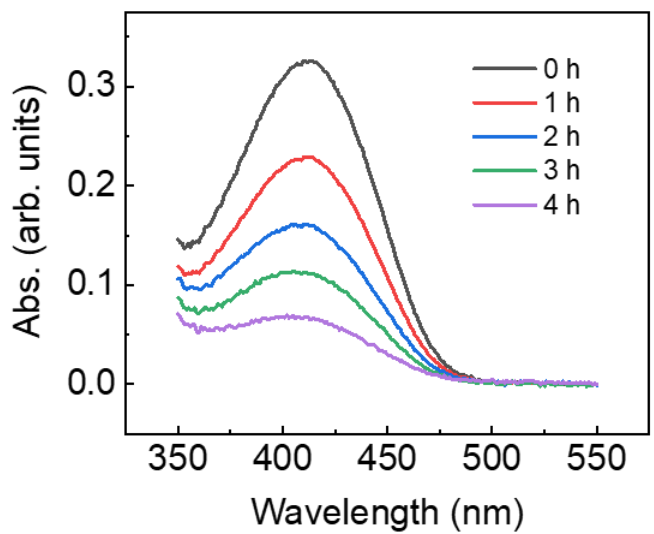

Figure S17. Absorption spectrum of $\mathrm{CH}_{2} \mathrm{O}$ solution as a function of time. 